\title{
XANES measurements probing the local order and electronic structure of $\mathrm{Pb}_{1-x} \mathrm{Ba}_{x} \mathrm{Zr}_{0.40} \mathrm{Ti}_{0.60} \mathrm{O}_{3}$ ferroelectric materials
}

\author{
A. Mesquita ${ }^{\mathrm{a}, \mathrm{b}, \mathrm{c}, *}$, A. Michalowicz ${ }^{\mathrm{b}}$, V.R. Mastelaro ${ }^{\mathrm{c}}$ \\ a Instituto de Geociências e Ciências Exatas, Universidade Estadual Paulista, Rio Claro, SP, Brazil \\ ${ }^{\mathrm{b}}$ Institut de Chimie et des Materiaux Paris Est, CNRS and Université Paris-Est, 94320 Thiais, France \\ 'Instituto de Física de São Carlos, Universidade de São Paulo, São Carlos, SP, Brazil
}

\section{A R T I C L E I N F O}

Article history:

Received 3 November 2014

Received in revised form 2 April 2015

Accepted 3 April 2015

Available online 9 April 2015

\section{Keywords:}

Ferroelectrics

Relaxor

X-ray absorption

Perovskite

Lead zirconate titanate

PBZT

\begin{abstract}
A B S T R A C T
In this study, the electronic and local structures of $\mathrm{Pb}_{1-x} \mathrm{Ba}_{x} \mathrm{Zr}_{0.40} \mathrm{Ti}_{0.60} \mathrm{O}_{3}$ ferroelectric ceramic samples were characterized using X-ray absorption near-edge structure (XANES) measurements. The analysis of XANES spectra collected at the Ti K- and L-edges showed that the substitution of $\mathrm{Pb}$ by Ba leads to a decrease in the local distortion around the $\mathrm{Ti}$ atoms in the $\mathrm{TiO}_{6}$ octahedron. The analysis of $\mathrm{O}$ K-edge XANES spectra and density of states $a b$ initio calculations showed that the hybridization between the $\mathrm{O} 2 p$ and $\mathrm{Pb} 6 s p$ states is related to the displacement of $\mathrm{Ti}$ atoms in the $\mathrm{TiO}_{6}$ octahedra. Based on these results, it is possible to determine that the degree of ferroelectricity in these samples and the manifestation of relaxor behavior are directly related to the weakening of $\mathrm{O} 2 p$ and $\mathrm{Pb} 6 s p$ hybridization.
\end{abstract}

(c) 2015 Elsevier B.V. All rights reserved.

\section{Introduction}

Lead zirconate titanate $\left(\mathrm{PbZr}_{1-y} \mathrm{Ti}_{y} \mathrm{O}_{3}\right.$, also referred to as PZT) ceramic systems have been extensively studied due to their unique properties, which permit a wide variety of applications such as in piezoelectric, pyroelectric and ferroelectric devices [1-4]. The PZT system exhibits a cubic structure at higher temperatures and three different structures at room temperature depending on the composition: tetragonal, orthorhombic or rhombohedral. According to the proposed phase diagram [5], at the titanium-rich side of the phase diagram, all compositions are tetragonal with $P 4 \mathrm{~mm}$ symmetry. On the other hand, depending on $x$ and the temperature, two rhombohedral phases, $R 3 \mathrm{~m}$, often referred to as FR(HT), and $R 3 c$, referred to as FR(LT), are known to occur in Zr-rich PZT ceramics [6]. The region between the tetragonal and rhombohedral phases $(y \sim 0.50)$ is called the morphotropic phase boundary (MPB) and is characterized by the presence of these two phases and monoclinic symmetry with the $\mathrm{Cm}$ space group, which is a subgroup of the $P 4 \mathrm{~mm}$ and $R 3 \mathrm{~m}$ space groups [7]. More recently, Glazer et al. performed neutron diffraction measurements; their analysis allowed for the elaboration of a new phase diagram with mixtures of rhombohedral and monoclinic symmetries on

* Corresponding author at: Instituto de Geociências e Ciências Exatas, Universidade Estadual Paulista, Rio Claro, SP, Brazil. the $\mathrm{Zr}$-rich side, tetragonal and monoclinic on the Ti-rich side, and three phases coexisting in the MPB region [8]. For all values of $y$, the PZT system exhibits long-range ferroelectric order, micrometer domain and/or domain wall structures, and does not show any frequency dispersion (relaxational effect) in the audio frequency range [9].

However, pure PZT ceramic materials are rarely applied in electronic devices, and a doping process is used to enhance the properties of this class of material $[5,10]$. For this purpose, $\mathrm{La}^{3+}$ cations have been used to replace the $\mathrm{Pb}^{2+}$ cations, forming a $\mathrm{Pb}_{1-x} \mathrm{La}_{x} \mathrm{Zr}_{1-y} \mathrm{Ti}_{y} \mathrm{O}_{3}$ (PLZT) system. It is well known that this substitution induces a peculiar diffuse phase transition with frequency dispersion. It is widely believed that both the $\mathrm{La}^{3+}$ aliovalent ions and/or oxygen vacancies (necessary to preserve charge neutrality) break the translational symmetry of the lattice and represent a type of disorder responsible for the formation of polar nanodomains and, consequently, the relaxor feature [9].

Another doping method has also been used to enhance the properties of the PZT ceramic system: the substitution of $\mathrm{Pb}^{2+}$ by $\mathrm{Ba}^{2+}$ cations, forming the $\mathrm{Pb}_{1-x} \mathrm{Ba}_{x} \mathrm{Zr}_{1-y} \mathrm{Ti}_{y} \mathrm{O}_{3}$ system. Since the publication of the phase diagram [11], several studies have been performed on this system due to its rich variety of interesting physical properties of both technological and fundamental importance [12-16]. In these papers, it has been reported that certain PBZT compositions present the characteristics of typical relaxor ferroelectrics $[9,16]$. Moreover, relaxor behavior 
was observed in our previous study concerning the $\mathrm{Pb}_{1-x} \mathrm{Ba}_{x} \mathrm{Zr}_{0.40} \mathrm{Ti}_{0.60} \mathrm{O}_{3}$ system with $x=0.50$ [17]. With a $\mathrm{Zr} / \mathrm{Ti}$ ratio of $65 / 35$, relaxor behavior is observed for 40 at.\% of $\mathrm{Ba}$, a higher amount compared to the amount of La in a PLZT system with the same $\mathrm{Zr} / \mathrm{Ti}$ ratio ( $\sim 8$ at.\% of La) which exhibits this behavior $[9,18]$. This difference between systems is not completely understood, although it is related to the fact that Ba substitution does not create vacancies because of its isovalent incorporation. Therefore, the appearance of relaxor behavior in the PBZT system could be related to defects in the structure caused by the difference between $\mathrm{Pb}$ and $\mathrm{Ba}$ ions [9].

The results of X-ray diffraction (XRD) in different relaxor materials with a perovskite structure have shown, in most cases, the existence of a cubic structure both above and below the temperature of maximum dielectric permittivity $\left(T_{m}\right)$ [19]. From the standpoint of local order, the use of different techniques for structural characterization such as XAS and Raman spectroscopy has shown the existence of a certain degree of disorder both above and below $T_{m}$. This degree of disorder is not compatible with a local structure with cubic symmetry as detected by XRD measurements [20-22]. Furthermore, it has been shown that the analysis of XAS measurements of elements with lower energy edges or low atomic number can provide information concerning the local order and electronic structure of different materials, which can be important for elucidating aspects about ferroelectricity [23-27].

The purpose of this study was to verify the role of the substitution of $\mathrm{Pb}^{2+}$ by $\mathrm{Ba}^{2+}$ ions in the local structure of the $\mathrm{Pb}_{1-x} \mathrm{Ba}_{x} \mathrm{Zr}_{0.40} \mathrm{Ti}_{0.60} \mathrm{O}_{3}$ ferroelectric material. This $\mathrm{Zr} / \mathrm{Ti}$ ratio was chosen because of the absence of studies in the literature describing the structure of a PBZT system with a Ti-rich composition. A correlation between the relaxor behavior observed in some $\mathrm{Ba}$ compositions and X-ray absorption near edge structure (XANES) measurements at the $\mathrm{Ti} \mathrm{K}$ - and $\mathrm{L}_{\mathrm{II}, \mathrm{III}}$-edges and the $\mathrm{O} \mathrm{K}$-edge is presented.

\section{Experimental procedures}

PBZT samples, of the nominal composition $\mathrm{Pb}_{1-x} \mathrm{Ba}_{x} \mathrm{Zr}_{0.40} \mathrm{Ti}_{0.60} \mathrm{O}_{3}$ (denoted as PBZT100x) with $x=0.00$ (PZT), 0.10, 0.20, 0.30, 0.35, 0.40 and 0.50 at.\%, were prepared by the conventional mixed oxide method. The oxides $\mathrm{PbO}, \mathrm{BaO}, \mathrm{ZrO}_{2}$ and $\mathrm{TiO}_{2}$, weighed according to stoichiometry, were mixed by ball milling in isopropyl alcohol for $5 \mathrm{~h}$. The slurry was dried and calcined in a covered alumina crucible at $850^{\circ} \mathrm{C}$ for $4 \mathrm{~h}$ and mixed by ball milling again for $5 \mathrm{~h}$. Ceramic bodies were then formed by uniaxial pressure, and fired at between $1100{ }^{\circ} \mathrm{C}$ and $1200^{\circ} \mathrm{C}$ for $2 \mathrm{~h}$ in a conventional electric furnace. The sintering process of the samples was performed in a $\mathrm{Pb}$-rich atmosphere to avoid losses in the stoichiometry.

In order to confirm the nominal compositions, an inductively coupled plasma (ICP) atomic emission spectrometer (ICP-AES Simultaneous CCD-VISTA-MPX; Varian) with radial configuration was used for the chemical analysis of two samples. The ICP measurements were performed on the PZT and PBZT10 samples and the following molar fraction compositions were obtained: 1.001 for $\mathrm{Pb}, 0.401$ for $\mathrm{Zr}$, and 0.595 for Ti (PZT sample) and 0.895 for $\mathrm{Pb}, 0.095$ for $\mathrm{Ba}, 0.411 \mathrm{for} \mathrm{Zr}$, and 0.605 for Ti (PBZT10 sample). This shows that the sample compositions after sintering remain quite similar to the nominal compositions. These compositions were also confirmed by XRD Rietveld refinement [17].

The titanium K-edge X-ray absorption spectra were collected at the LNLS (National Synchrotron Light Laboratory) facility using the D04B-XAS1 beamline. The LNLS storage ring was operated at $1.36 \mathrm{GeV}$ and $100-160 \mathrm{~mA}$. The sample pellets obtained after sintering were ground for the XAS measurements. The XAS data were collected at the Ti K-edge $(4966 \mathrm{eV})$ in transmission mode at room temperature using a $\mathrm{Si}(111)$ channel-cut monochromator. Ionization chambers were used to detect the incident and transmitted flux. XANES spectra at the Ti K-edge were recorded for each sample between 4910 and $5200 \mathrm{eV}$ using energy steps of $0.5 \mathrm{eV}$. To provide good energy reproducibility during XANES data collection, the energy calibration of the monochromator was checked during the collection of the sample data using a Ti metal foil. Titanium $\mathrm{L}_{\mathrm{II}, \mathrm{III}}$-edges and oxygen K-edge spectra were measured using the SGM beamline at the Canadian Light Source synchrotron facility. These XANES spectra (453 and $543 \mathrm{eV}$, respectively) were collected at room temperature in electron yield mode. Normalizations of the XANES spectra were performed using the Multi-Platform Applications for X-ray absorption (MAX) program [28]. The theoretical XANES spectra and projected density of states (DOS) were calculated using FEFF8.2 code [29].

\section{Results and discussion}

In order to investigate the local order around a Ti atom, Ti Kedge XANES measurements were performed for the PBZT samples; the spectra are presented in Fig. 1 and its inset. The pre-edge region of the K-edge XANES spectra of some transition metal oxides is characterized by a pronounced feature, several volts before the main rising edge $[21,30,31]$. In transition metal oxides that crystallize in centrosymmetric structures, this pre-edge feature is very small or absent, whereas in non-centrosymmetric structures it can be quite large $[21,30,31]$.

The inset in Fig. 1 shows the transitions in the spectra, labeled A, B and C. According to the Vedrinskii et al. the physical origin of the pre-edge feature labeled $A$ is due to quadrupolar transitions of $t_{2 g}$-type molecular orbitals located in the absorption atom (Ti) [32]. These authors also show that B transitions are caused by hybridization of $p$ - and $d$-symmetry states at the Ti atom under the influence of neighboring oxygen atoms. This takes place if the inversion symmetry is broken relative to the absorbing atom's instantaneous position [32]. Moreover, the high intensity of this transition is considered to be a qualitative spectroscopic indication of ferroelectricity in a perovskite structure crystal.

Peak B can be successfully used to determine the mean-square (static or dynamic) displacements of Ti atoms from the instantaneous centers of coordination polyhedrons [32-34]. The pre-edge feature labeled $C$ in Fig. 1 has been shown to be caused by a Ti $1 s$ electron transition to the unoccupied $3 d$-origin $e_{g}$-type molecular orbital of $\mathrm{TiO}_{6}$ polyhedra neighboring the absorbing $\mathrm{Ti}$ atoms, which are weakly affected by the core hole potential [32]. The area of the $C$ peak presents no strong dependence on small displacements of the atoms from their sites in the cubic crystal lattice. However, it changes significantly when $4 d$ atoms appear in the vicinity of the absorbing $\mathrm{Ti}$ atom, for instance, $\mathrm{Zr}$ atoms in the PZT solid solution [32].

As shown in Fig. 1, the intensity of peak B decreases as the Ba at.\% increases, which means that a Ti atom moves to the center of a $\mathrm{TiO}_{6}$ octahedron. Our previous structural study on $\mathrm{Pb}_{1-x} \mathrm{Ba}_{x} \mathrm{Zr}_{0.65} \mathrm{Ti}_{0.35} \mathrm{O}_{3}$ (PBZT) samples ( $\mathrm{Zr}$-rich side) showed that this transition presents no variation in its intensity because, in that case, the Ti atoms are displaced in the [111] crystallographic direction due to the rhombohedral symmetry of these samples [35]. The PBZT samples of the present study exhibit a tetragonal symmetry and a Ti atom is displaced in the [001] direction and, for this reason, peak B decreases in intensity with increasing Ba content.

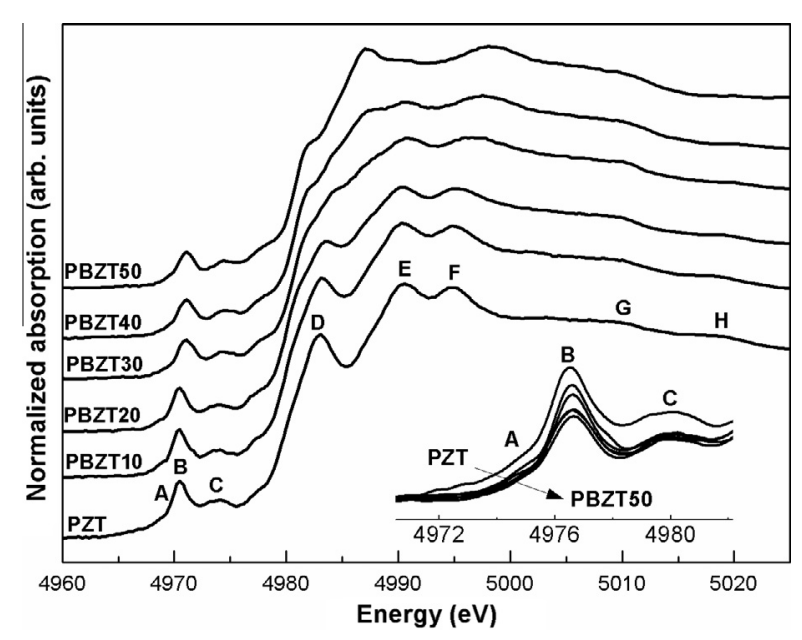

Fig. 1. Ti K-edge XANES spectra for PBZT samples. The inset shows in detail features $\mathrm{A}, \mathrm{B}$ and $\mathrm{C}$. 
Although previous XRD results have shown that a PBZT50 sample presents cubic symmetry at room temperature, the current XANES analysis shows that Ti atoms in this sample are also displaced from their centrosymmetric position [17]. Even though the intensity of B for this sample is smaller than in the PZT sample, it is high enough to indicate a displacement from the center of the $\mathrm{TiO}_{6}$ octahedron, unexpected for Pm-3m local symmetry [20]. This apparent disagreement between the XRD and XAS results, even in an ideal perovskite cubic structure in which the crystal retains its higher symmetry $(\mathrm{Pm}-3 \mathrm{~m})$, indicates that atoms may move around their ideal position $[20,36]$.

Differences in the local symmetries observed by the XAS and XRD techniques have also been observed by other authors. Sicron et al. reported results consistent with a cubic symmetry through the X-ray diffraction technique, but with a local tetragonal symmetry using the XAS technique in the $\mathrm{PbTiO}_{3}$ compound studied above its Curie temperature [37]. XAS analyses at the Ti K-edge and $\mathrm{Pb}$

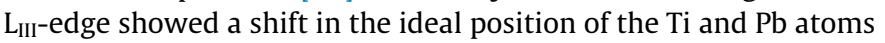
above the Curie temperature, whereas the $\mathrm{Ti}$ and $\mathrm{Pb}$ atoms occupy their ideal positions in the analysis by X-ray diffraction. Teslic and Egami $[38,39]$ also reported a discrepancy when they studied the local atomic structure of $\mathrm{PbZr}_{1-x} \mathrm{Ti}_{x} \mathrm{O}_{3}, \mathrm{~Pb}\left(\mathrm{Mg}_{1 / 3} \mathrm{Nb}_{2 / 3}\right) \mathrm{O}_{3}$ and $\mathrm{Pb}_{1-x} \mathrm{La}_{x} \mathrm{Zr}_{y} \mathrm{Ti}_{1-y} \mathrm{O}_{3}$ systems through X-ray diffraction and neutron scattering measurements. Their structural studies yield evidence of a slight local deviation from the crystallographic lattice periodicity and local chemical ordering. Finally, a similar apparent discrepancy between the XRD long range order and local symmetry was observed in $\mathrm{BaTiO}_{3}$ phase transitions by Tsuda et al. using convergent beam electron diffraction [40].

Thus, the apparent discrepancy between the results from XAS and from XRD can be explained in terms of the level of disorder that these techniques can detect. In XAS, the physical process involved in the absorption occurs on the order of $10^{-15} \mathrm{~s}$ [37]. This time is less than the time scale of the changes in the system, enabling the observation of dynamic and fast disorder processes [37]. Regarding XRD, the lack of observation of the local distortion is related to the structural model used in the refinement of the Bragg peak intensities, a periodic pattern where local distortions are not taken into consideration [20]. As a result, XAS for allows a better visualization of local distortions than XRD, which provides information about the average structure [20].

The area under peak B was calculated using a Lorentz function for the PLZT spectra, and the displacement of the Ti atom from the centrosymmetric position within the $\mathrm{O}$ octahedron was evaluated using an empirical relation [33,41]. For polycrystalline perovskites, the off-center displacement $d$ (static and/or dynamic) of the $\mathrm{Ti}$ atom from the center of the $\mathrm{TiO}_{6}$ octahedron is related to the area $A$ under the corresponding peak in the $1 s-3 d$ transition region by $[21,33,41]$.

$A=\frac{\gamma}{3} d^{2}$

where $\gamma$ is a proportionality constant measured for different perovskites. As can be observed in Fig. 2, as the amount of $\mathrm{Ba} 2+$ increases, the displacement of the Ti atom from the centrosymmetric position within the $\mathrm{O}$ octahedron decreases continually up to $50 \mathrm{Ba}$ at.\%. However, a local distortion remains at all Ba concentrations in spite of the expected cubic crystal structure. In principle the Ti off-center displacement should be evaluated more precisely by an EXAFS refinement of the octahedron $\mathrm{TiO}_{6}$ first shell EXAFS signal. However, the presence of the Ba LIII-edge $282 \mathrm{eV}$ above the Ti $\mathrm{K}$ edge prohibits the use of EXAFS as a quantitative probe of the $\mathrm{TiO}_{6}$ local distortion in this case. Theoretical calculations of the Ti K-edge XANES spectra, with either regular or distorted $\mathrm{TiO}_{6}$ octahedra in samples similar to PLZT, have been published [42-44]. They confirm our experimental results.

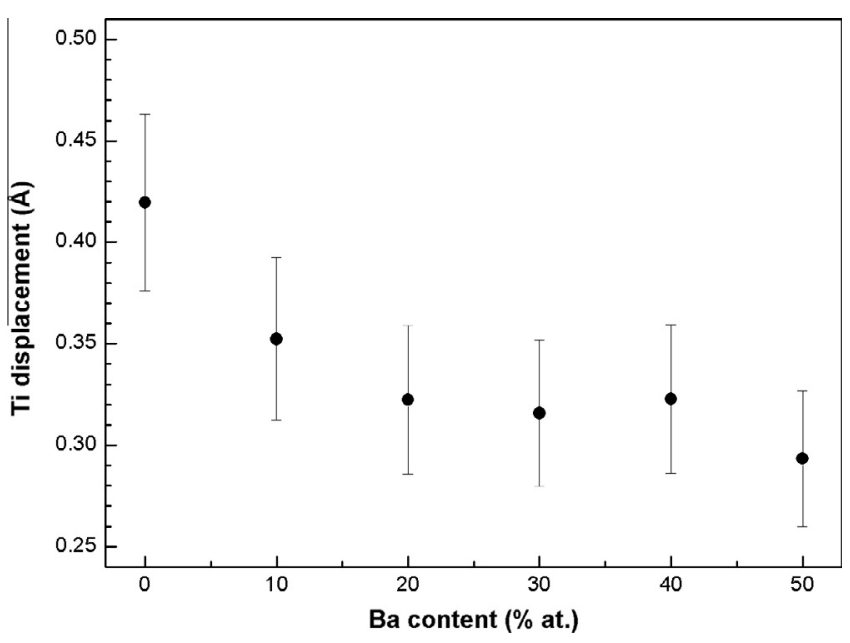

Fig. 2. Ti displacement as a function of the Ba content calculated from feature B.

Recent studies have described the importance of $B$ atom displacement in the $\mathrm{BO}_{6}$ octahedron in compositional phase transitions (as in the case of the incorporation of a Ba atom) between different ferroelectric phases, as well as the normal-to-relaxor ferroelectric transition [45,46]. Larger $B$ atom off-center displacements allow the overbonding of oxygen atoms to be alleviated by motion of the $B$ atoms away from the $\mathrm{O}$ atom, tending to stabilize normal ferroelectric phases relative to relaxor or other disordered phases [46]. It also has been shown that the application of external pressure diminishes off-centering displacements [45,47]. These effects induce relaxor behavior and greatly increase the frequency dispersion $[46,48]$.

With respect to peak $C$ in Fig. 1, which is related to the second neighbors of a $\mathrm{Ti}$ atom, no significant variations in intensity or shape were detected with the addition of $\mathrm{Ba}$. The absence of variations in this peak suggests no substitution at the $B$ site of $B_{6}$ octahedrons, because the $\mathrm{Zr} / \mathrm{Ti}$ ratio was kept constant and the $\mathrm{Ba}$ atom preferably replaces the $\mathrm{Pb}$ atom, rather than the Ti atom [20].

The transitions labeled D, E, F, G and $\mathrm{H}$ beyond the absorption edge are related to the electronic transitions and atomic structure of the second and third neighbors of the Ti atom within a distance of up to $8 \AA$ from this atom $[20,43]$. As the Ba content increases, the peak labeled $\mathrm{D}$ disappears and the $\mathrm{E}$ and $\mathrm{F}$ peaks become more broadened, mainly for the PBZT40 and 50 samples. The changes

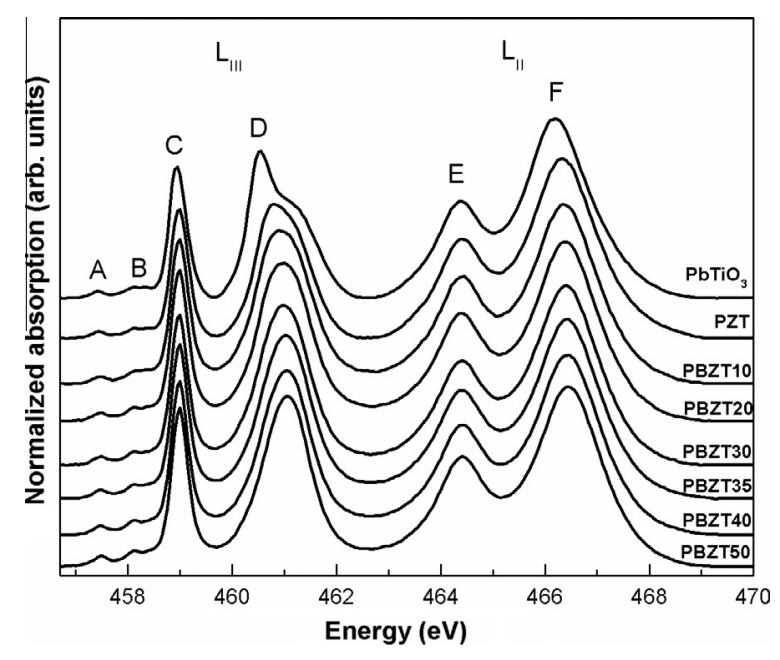

Fig. 3. Ti $\mathrm{L}_{\mathrm{II}, \mathrm{III}}$-edge XANES spectra for PBZT samples. 
in this region can be attributed to the substitution of a large amount of $\mathrm{Pb}^{2+}$ and $\mathrm{Ba}^{2+}$ atoms or to the crystal structure changes induced by this substitution [43].

Fig. 3 presents the XANES spectra at the Ti $\mathrm{L}_{\text {III,II }}$-edges of the PBZT samples. In Fig. 3, the $\mathrm{PbTiO}_{3}$ XANES spectrum is also presented for comparison. Fig. 4 shows in more detail the features between 460 and $462 \mathrm{eV}$, which correspond to peak D in Fig. 3 after subtracting the background using two arctangent functions. The features labeled A and B are related to forbidden transitions in the L-S coupling (spin-orbit coupling) but become allowed due to the pd multipolar interactions [49]. Features C and D occur because, in the $\mathrm{Ti} \mathrm{L}_{\mathrm{III}}$-edge, the $3 d$ band splits into two subbands: $t_{2 g}$ (peak C) and $e_{g}$ (peak D) [50]. The Ti $3 d e_{g}$ subband (D) splits into $3 d_{x^{2}-y^{2}}$ and $3 d_{z^{2}}$ orbitals that point to the four side-corners and the two apex $\mathrm{O}$ ions of the octahedron, respectively [50]. This implies that the variation in the Ti-O bond lengths due to the Ti off-center displacement has a direct effect on $\mathrm{D}$. In contrast, the $3 d_{x y}, 3 d_{y z}$, and $3 d_{z x}$ orbitals of the $t_{2 g}$ subband point in directions between the $\mathrm{O}$ ions, so $\mathrm{C}$ is not affected by the displacement of a Ti atom [50]. The crystal field at the $\mathrm{L}_{\mathrm{II}}$-edge also splits the $3 d$ band into $t_{2 g}$ and $e_{\mathrm{g}}$ subbands and a similar splitting of the $e_{\mathrm{g}}$ states in the F peak also occurs at the $\mathrm{L}_{\mathrm{II}}$-edge. However, it is not well-resolved due to the lifetime-related broadening of the $\mathrm{L}_{\mathrm{II}}$-edge [50].

As can be seen in Figs. 3 and 4, the splitting between the $e_{g}$ orbitals becomes less discernible as $\mathrm{Zr}$ and $\mathrm{Ba}$ atoms are added to the $\mathrm{PbTiO}_{3}$ structure. This means that the degree of distortion of the $\mathrm{TiO}_{6}$ octahedron is reduced as the concentration of $\mathrm{Ba}$ atoms increases, which agrees with the results at the Ti K-edge.

Jan et al. attributed a similar behavior observed with the $\mathrm{Pb}_{1-x} \mathrm{Ca}_{x} \mathrm{TiO}_{3}$ compound to the substitution of $\mathrm{Ti}$ by $\mathrm{Ca}$ atoms, which decreases the Ti displacement in relation to its centrosymmetric position [27]. On the other hand, this $e_{g}$ orbital splitting was not observed in the XANES spectra of $\mathrm{Ba}_{1-x} \mathrm{Sr}_{x} \mathrm{TiO}_{3}$ (BST) compounds, and the peak labeled D was adjusted by a simple Gaussian function [51]. In that case, the absence of $e_{g}$ splitting was attributed to an insignificant tetragonal distortion or a lower $c / a$ ratio, which means that the Ti atoms occupy the centrosymmetric positions of the $\mathrm{TiO}_{6}$ octahedra [51].

Even for compositions with higher concentrations of $\mathrm{Ba}$, in which $\mathrm{D}$ is large and asymmetric, the adjustment considering just one peak could not be performed in the same region of the experimental spectra shown in Fig. 4.

The origin of this splitting in the $e_{g}$ states is a controversial subject in the literature $[27,51,52]$. Recently, Kruger studied the Ti

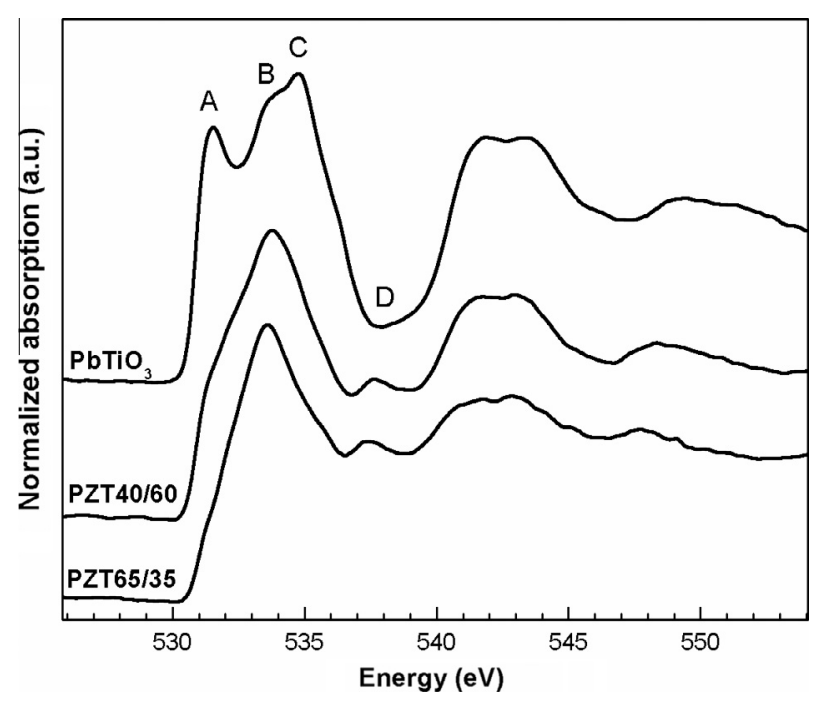

Fig. 5. O K-edge XANES spectra for the compounds $\mathrm{PbTiO}_{3}, \mathrm{PbZr}_{0.65} \mathrm{Ti}_{0.35} \mathrm{O}_{3}$ (PZT65/ 35) and $\mathrm{PbZr}_{0.40} \mathrm{Ti}_{0.60} \mathrm{O}_{3}(\mathrm{PZT} 40 / 60)$.

$\mathrm{L}_{\mathrm{II}, \mathrm{III}}$-edge spectra of $\mathrm{SrTiO}_{3}$ and $\mathrm{TiO}_{2}$ compounds [53]. According to this author, the distortion of $\mathrm{TiO}_{6}$ octahedra is not a sufficient condition for $\mathrm{L}_{\mathrm{III}}-e_{g}$ peak splitting, since there is no splitting for an isolated (distorted) $\mathrm{TiO}_{6}$ octahedron. Moreover, he showed that in an ideal rutile made from an undistorted octahedral, splitting on the $\mathrm{L}_{\mathrm{III}}-e_{\mathrm{g}}$ peak can be observed and is comparable to the width of the splitting in a real rutile [53]. He concluded that the characteristic $\mathrm{L}_{\mathrm{III}}-e_{\mathrm{g}}$ peak splitting in $\mathrm{TiO}_{2}$ is a long-range band-structure effect, which reflects the crystal structure of $\mathrm{TiO}_{2}$ on a length scale of about $1 \mathrm{~nm}$ [53].

Some studies have also shown that electronic properties of $\mathrm{O}$ atoms can provide more direct information about ferroelectric stability $[27,54]$. Thus, the XANES spectra at the O K-edge of PBZT samples were measured and are presented in Figs. 5 and 6.

First, the O K-edge XANES spectra of the $\mathrm{PbTiO}_{3}, \mathrm{PbZr}_{0.65} \mathrm{Ti}_{0.35} \mathrm{O}_{3}$ (PZT65/35) and $\mathrm{PbZr}_{0.40} \mathrm{Ti}_{0.60} \mathrm{O}_{3}$ (PZT40/60) compounds were analyzed. These compounds were chosen to evaluate the influence of $\mathrm{Zr}$ addition on the $\mathrm{PbTiO}_{3}$ electronic structure, and also how it can be correlated to the ferroelectric character of these samples.

As is shown in Fig. 5, as Ti atoms are substituted by $\mathrm{Zr}$ atoms in $\mathrm{PbTiO}_{3}$ (PZT samples) the intensity of $\mathrm{A}$ and $\mathrm{C}$ decreases, whereas

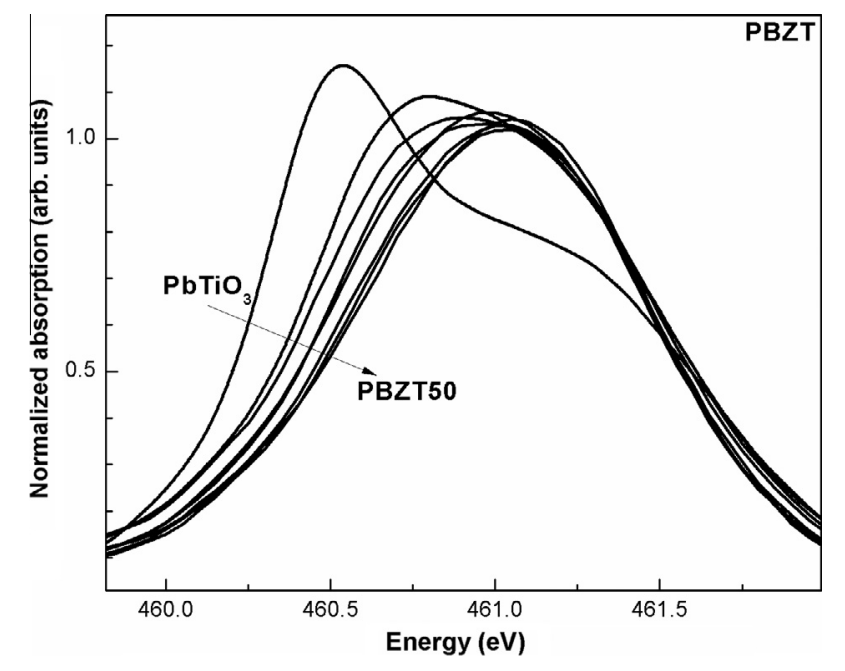

Fig. 4. Magnified feature D for PBZT samples after background subtraction.

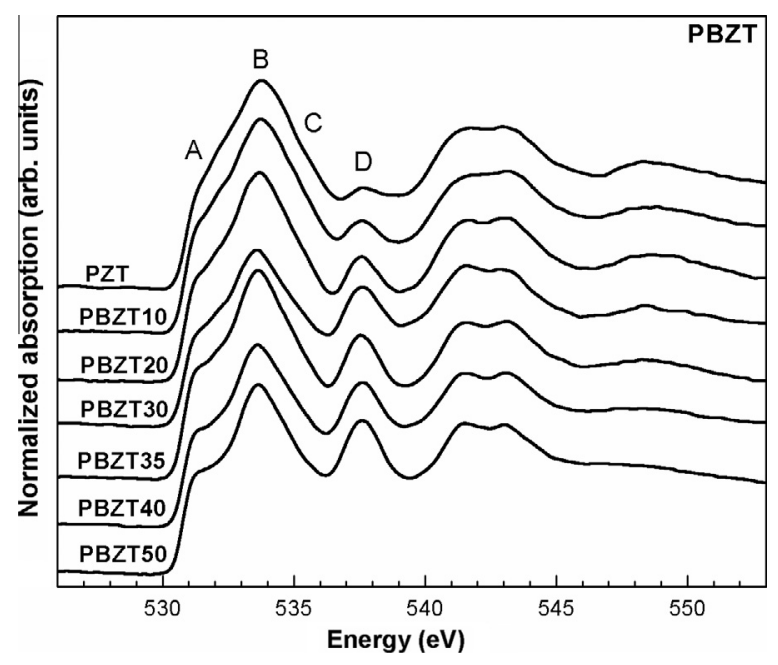

Fig. 6. O K-edge XANES spectra for PBZT samples. 


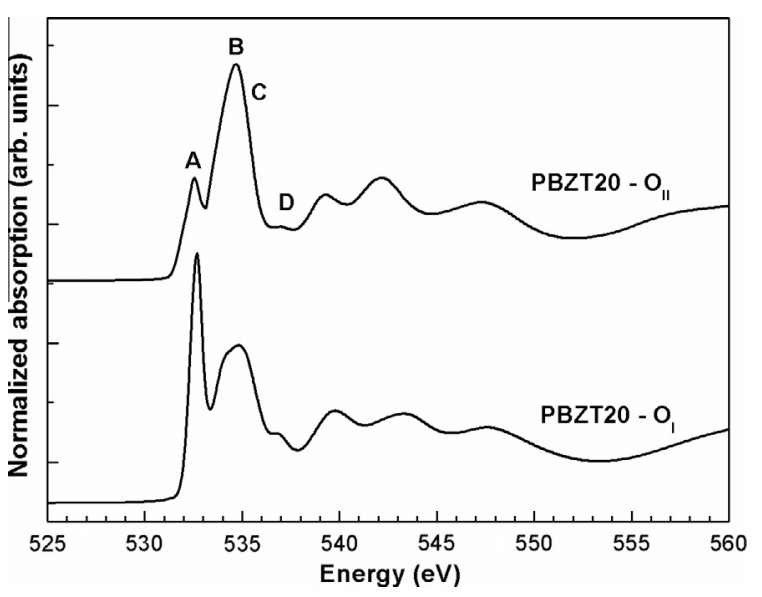

Fig. 7. Calculated O K-edge XANES spectra for the PBZT20 sample using FEFF 8.2 code.

the intensity of B remains constant in the two PZT samples. Feature D is only observed in the spectra of PLZT samples. Fig. 6 shows the O K-edge spectra of PBZT samples as a function of Ba content.

In Fig. 7, the theoretical O K-edge spectra of PBZT20 compounds obtained from the FEFF 8.2 code [29] are presented. The O K-edge XANES spectra were calculated in terms of a cluster derived from the average structure of the PBZT20 compound determined from previous XRD measurements [17]. Clusters with sizes of up to eight shells around the absorber (oxygen atom) were used. The calculation was performed with the default settings of the FEFF 8.2 code. Because of the symmetry of the tetragonal perovskite cell, oxygen atoms occupy two sites in the $P 4 \mathrm{~mm}$ space group [17]. Thus, in Fig. 7, two XANES spectra are shown which are relative to the neighborhood of oxygen atoms occupying positions $1 / 2,1 / 2$,

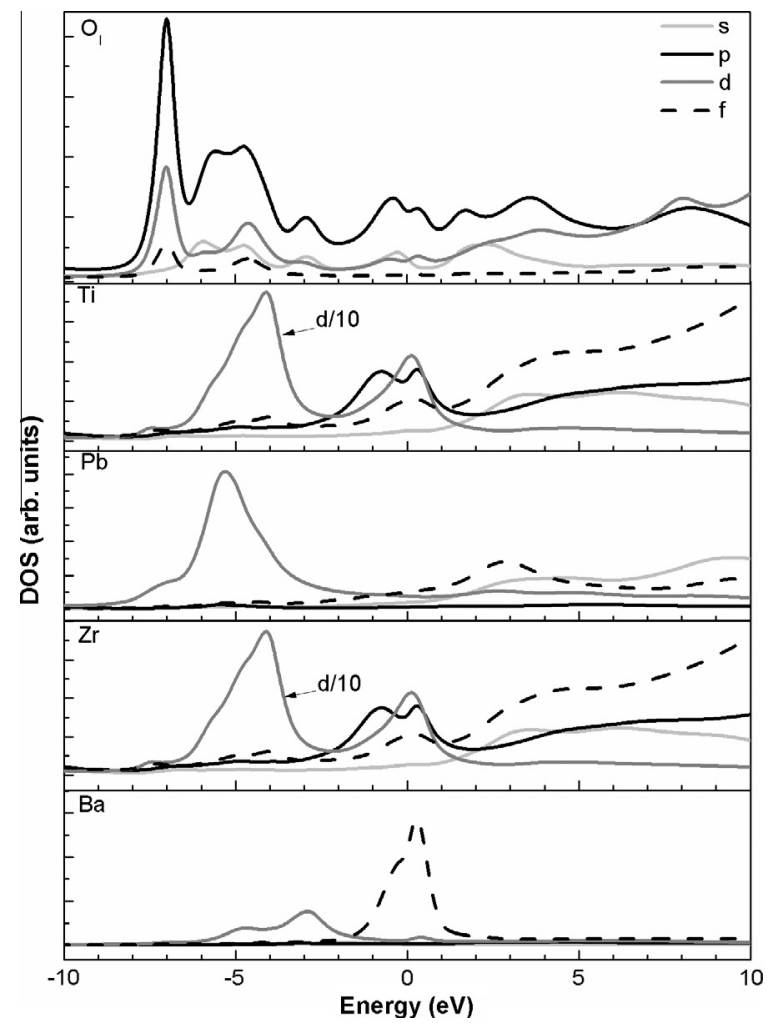

Fig. 8. Projected DOS of the constituent elements using FEFF 8.2 code from $O_{I}$ oxygen.
$0+\delta_{\mathrm{O}(1)}$ (denoted by $\mathrm{O}_{\mathrm{I}}$ ) and $1 / 2,0,1 / 2+\delta_{\mathrm{O}(2)}$ (denoted by $\mathrm{O}_{\mathrm{II}}$ ). According to the XRD results obtained in our previous study [17], $\delta_{\mathrm{O}(1)}$ and $\delta_{\mathrm{O}(2)}$ for PBZT20 are equal to $0.094(4)$ and $0.080(3)$, respectively. As can be observed on comparing Figs. 5-7, the XANES spectrum calculated from the $\mathrm{O}_{\text {II }}$ oxygen reasonably reproduces the features $A, B, C$ and $D$ and the peaks positioned between 540 and $550 \mathrm{eV}$.

In order to better assign the different features observed in the $\mathrm{O}$ K-edge XANES spectra of the PBZT samples, we undertook $a b$ initio quantum-theoretical calculations. Figs. 8 and 9 present the local density of states (s-, p-, d- and f-projected DOS) of the constituents oxygen, titanium, lead, zirconium and barium considering the $\mathrm{O}_{I}$ and $\mathrm{O}_{\mathrm{II}}$ oxygen positions. The DOS calculations were developed under equivalent conditions to those used to calculate the theoretical XANES spectrum of the PBZT20 compound. We calculated the projected DOS of the PBZT20 sample to evaluate the local density contribution of states of all atoms, including barium atoms. The energy scale of the local DOS was as calculated by the FEFF 8.2 code, and the experimental XANES spectrum was then shifted to be aligned to the 02 p-projected DOS in order to compare the specific peak positions.

The features observed in the $\mathrm{O}$ K-edge XANES spectra are due to transitions from $\mathrm{O} 1 s$ states to unoccupied $\mathrm{O} 2 p$ states, which are hybridized with Ti $3 d$ and $4 s p, \mathrm{Zr} 4 d$ and $\mathrm{Pb} 6 s p$ states [51]. As has been noted in the literature for similar perovskite ferroelectric compounds, the $\mathrm{O} 2 p$ - projected DOS resembles the experimental O K-edge calculated XANES spectra of the PBZT20 sample $[26,51,55]$. Moreover, we observe that the first peak in the $\mathrm{O} p$ DOS between -7.0 and $-2.0 \mathrm{eV}$ coincides with the position of the maxima of Ti $3 d$ DOS calculated from both the $\mathrm{O}_{\text {I }}$ and $\mathrm{O}_{\text {II }}$ oxygen positions, indicating that features $\mathrm{A}, \mathrm{B}$ and $\mathrm{C}$ result mainly from the transitions of the $\mathrm{O} 1 \mathrm{~s}$ orbital to antibonding $\mathrm{O} 2 p$ states hybridized with Ti $3 d$ orbitals. Note that in Figs. 8 and 9 the Ti $3 d$ and $\mathrm{Zr}$ $4 d$ DOS intensity is divided by 10 in order to compare the shape of

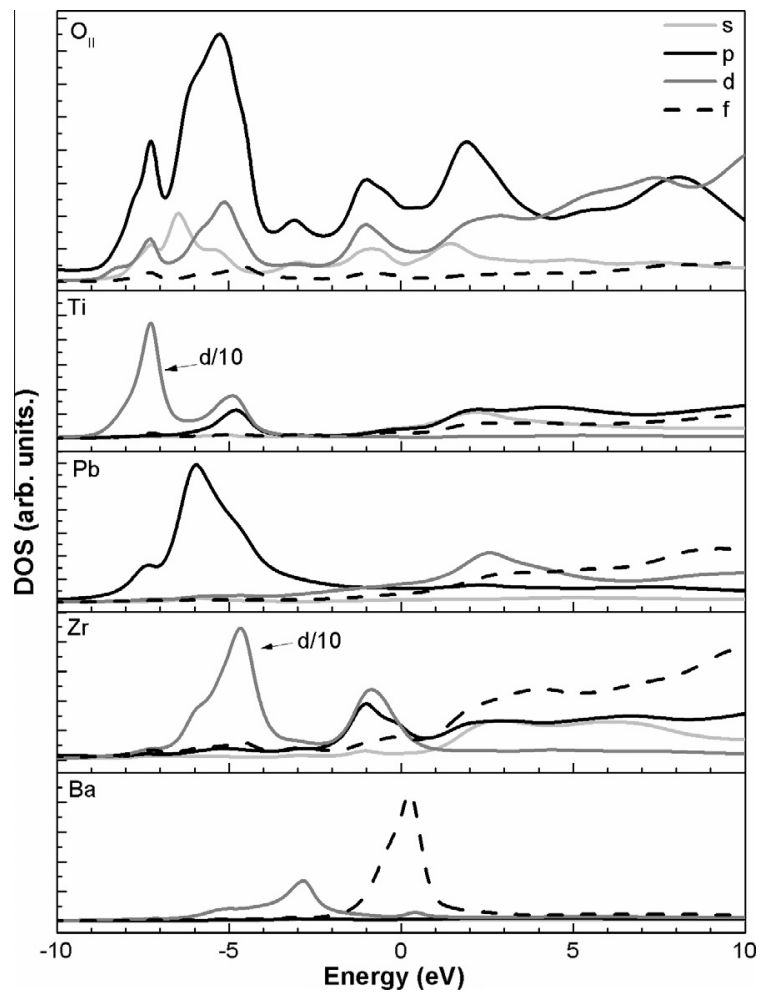

Fig. 9. Projected DOS of the constituent elements using FEFF 8.2 code from $\mathrm{O}_{\text {II }}$ oxygen. 
the symmetry-projected DOS on a common intensity scale. We also observed a contribution of the hybridization between $\mathrm{O} 2 p$ and $\mathrm{Pb}$ $6 p$ and $\mathrm{Zr} 4 \mathrm{~d}$ states $[26,51,55]$. Based on these calculations, we can also infer that peak $\mathrm{D}$ (which is not observed in the $\mathrm{PbTiO}_{3}$ XANES spectrum; its intensity increases as the Ba content increases) arises mainly with $\mathrm{O} 2 p$ hybridized with $\mathrm{Ti} 3 d$, $\mathrm{Zr} 4 d$ and Ba $5 d$; peaks between 540 and $550 \mathrm{eV}$ arise from a hybridization of $\mathrm{O} 2 p$ with Ti $4 s p d f, \mathrm{~Pb} 6 s / 5 d 4 f$, and $\mathrm{Zr} 4 s p d$ states.

Based on these interpretations, the analysis of the XANES results shows that the addition of $\mathrm{Zr}$ atoms leads to a reduction in the number of unoccupied $\mathrm{O} 2 p-\mathrm{Ti} 3 d$ states [51]. Regarding feature D, as it occurs due to hybridization of $\mathrm{O} 2 p$ with $\mathrm{Zr} 4 d$ states, it is only observed in PZT samples and its lower intensity is due to the effect of the weakening of the hybridization between the $0 p$ and $\mathrm{Zr} d$ states compared to the hybridization of $\mathrm{O} p$ states with Ti $d$ states [56]. Concerning the effect on the electronic structure of PBZT caused by the addition of Ba to the PZT40/60 sample in substituting $\mathrm{Pb}$ atoms (Fig. 6) the intensity of feature $\mathrm{B}$ decreases whereas features $A$ and $C$ do not vary significantly. A decrease in the width of the feature between 540 and $545 \mathrm{eV}$ and the reduction in the intensity of the peak between 547 and $553 \mathrm{eV}$ are related to reduced hybridization of $\mathrm{O} 2 p$ with Ti $4 s p d f$, $\mathrm{Pb} 6 s / 5 d 4 d$ or $\mathrm{Zr} 4 s p d$ states [57].

Jan et al. observed that the hybridization of $\mathrm{O} 2 p$ and Ti $3 d$ in $\mathrm{Pb}_{x} \mathrm{Sr}_{1-x} \mathrm{TiO}_{3}$ and of $\mathrm{Pb} 6 s p$ and $\mathrm{Ba} 5 d$ in $\mathrm{Pb}_{x} \mathrm{Ba}_{1-x} \mathrm{TiO}_{3}$ decreases as the concentration of $\mathrm{Sr}$ increases [51]. They explain this decrease in terms of the electronegativity of $\mathrm{Sr}(0.95)$, which is less than that of $\mathrm{Pb}$ (2.33) and causes charge transfer from $\mathrm{Sr}$ to $\mathrm{Pb}$. Such a transfer reduces the positive charge of the $\mathrm{Pb}$, weakening its attractive Coulomb potential and reducing the hybridization between the 0 $2 p$ states and $\mathrm{Pb} 6 s p$ [51].

Thus, following these analyses, the addition of $\mathrm{Ba}$, which has a lower electronegativity (0.89) than $\mathrm{Pb}$ (2.33), will cause a reduction in the hybridization between the $02 p$ states and $\mathrm{Pb} 6 s p$ states. In the case of $\mathrm{Zr}$ addition to $\mathrm{PbTiO}_{3}$, the electronegativity of $\mathrm{Zr}$ (1.33) is less than that of $\mathrm{Ti}$ (1.54), explaining the decrease in the intensity of feature $\mathrm{C}$ (hybridization $\mathrm{O} 2 p-\mathrm{Ti} 3 d$ ) as well as the increase in the intensity of feature $\mathrm{D}$ (hybridization $\mathrm{O} 2 p-\mathrm{Zr} 4 d$ ).

Miyazawa et al. [54] studied the relation between the transition metals present at the $B$ site and ferroelectricity for a series of $A B \mathrm{O}_{3}$ type perovskites with $A=\mathrm{Pb}, \mathrm{Ba}$ and $\mathrm{K}$ and $B=\mathrm{Ti}, \mathrm{Zr}, \mathrm{Nb}$, Ta and $\mathrm{Hf}$. They showed that hybridization between the $\mathrm{Pb} 6 p$ states and the $\mathrm{O}$ $2 p$ states is crucial for large displacements and the high degree of ferroelectricity in $\mathrm{PbTiO}_{3}$. According to Cohen [47], the hybridized states between $\mathrm{Pb}$ and $\mathrm{O}$ lead to a large deformation that stabilizes the tetragonal phase. Thus, the reduction in the degree of hybridization between the $\mathrm{O} 2 p$ states and $\mathrm{Pb} 6 s p$ states, as Ti atoms are substituted by $\mathrm{Zr}$ or when $\mathrm{Pb}$ atoms are replaced by $\mathrm{Ba}$, could be directly related to changes in the ferroelectric behavior of PBZT.

When replacing $\mathrm{Ti}$ by $\mathrm{Zr}$ in $\mathrm{PbTiO}_{3}$, i.e. forming the PZT compound, it is well-known that, with respect to $\mathrm{Zr}$ concentration, PZT samples present normal ferroelectric behavior. As has been shown before, no variation was observed in the hybridization between $02 p$ and $\mathrm{Pb} 6 s p$ states as the $\mathrm{Zr}$ concentration increased, which may be a characteristic of samples presenting normal ferroelectric behavior [47].

As the concentration of Ba increases in PZT4060, the observation of a decrease in the hybridization between the states $\mathrm{O} 2 p$ and $\mathrm{Pb} 6 s p$ coincides with the PBZT sample in which ferroelectric relaxor behavior begins to be observed [17]. Thus, this effect can be directly related to a modification in the ferroelectric phase transition from normal to relaxor.

\section{Conclusions}

In this study, we performed XANES measurements to probe the local order of PBZT samples and to correlate the results with the ferroelectric properties of these materials. Ti K-edge XANES measurements showed that Ba incorporation into the PZT structure leads to diminished local distortion of the $\mathrm{Ti}$ atoms in relation to $\mathrm{O}$ atoms. Moreover, we observed a reduction in Ti displacement from $\mathrm{TiO}_{6}$ centrosymmetric positions as the $\mathrm{Ba}$ concentration increased. Ti $\mathrm{L}_{\mathrm{III}}$-edge XANES measurements for PBZT samples confirmed this statement.

XANES spectra measured in the $\mathrm{O}$ K-edge revealed a reduction in the degree of hybridization between the $02 p$ states with the $\mathrm{Pb} 6 s p$ states as the concentration of Ba increased in the PZT system, which coincided with relaxor behavior with a higher Ba content. However, no variation in hybridization between these states was observed when $\mathrm{Zr}$ atoms were added to $\mathrm{PbTiO}_{3}$. Unlike the $\mathrm{PbZr}_{1-x} \mathrm{Ti}_{x} \mathrm{O}_{3}$ system, the $\mathrm{BaZr}_{1-x} \mathrm{Ti}_{x} \mathrm{O}_{3}$ system presented relaxor behavior depending on the concentration of $\mathrm{Zr}$. In this case, the interactions between the $\mathrm{Ba}$ and $\mathrm{O}$ atoms in $\mathrm{BaTiO}_{3}$ were completely ionic, which means there was no hybridization between the states of these atoms. It has been shown that hybridization between $\mathrm{O} 2 p$ and $\mathrm{Pb} 6 s p$ states is crucial for large displacements of atoms and a high degree of ferroelectricity. Thus, the weakening of hybridization is related with the appearance of relaxor behavior.

\section{Acknowledgments}

The authors are grateful to the funding agencies FAPESP and CAPES and to Dr. M.I.B. Bernardi for the ICP measurements. The presented research was partially carried out at the LNLS National Laboratory of Synchrotron Light, Brazil, and at the Canadian Light Source.

\section{References}

[1] Z. Zhang, W. Yu, Z. Shi, Y. Shen, D. Zhang, K. Li, Z. Yang, J. Nanosci. Nanotechnol 15 (2015) 3098-3102.

[2] S. Moharana, S. Bhalla, JIMSS 26 (2015) 247-259.

[3] J.I. Yang, R.G. Polcawich, L.M. Sanchez, S. Trolier-McKinstry, J. Appl. Phys. 117 (2015) 014103.

[4] Y. Xu, Ferroelectrics Materials and Their Applications, Elsevier Science Publishers B.V, Amsterdan, 1991.

[5] B. Jaffe, W.R. Cook, H. Jaffe, Piezoelectric Ceramics, Academic Press, London and New York, 1971.

[6] J. Frantti, S. Ivanov, S. Eriksson, H. Rundlof, V. Lantto, J. Lappalainen, M. Kakihana, Phys. Rev. B 66 (2002) 064108.

[7] B. Noheda, D.E. Cox, G. Shirane, R. Guo, B. Jones, L.E. Cross, Phys. Rev. B 63 (2001) 014103.

[8] N. Zhang, H. Yokota, A.M. Glazer, P.A. Thomas, Acta Crystallogr. B 67 (2011) 386-398.

[9] M.H. Lente, E.N. Moreira, D. Garcia, J.A. Eiras, P.P. Neves, A.C. Doriguetto, V.R Mastelaro, Y.P. Mascarenhas, Phys. Rev. B 73 (2006) 054106.

[10] L. Kozielski, M. Adamczyk, A. Lisinska-Czekaj, T. Orkisz, M. Piechowiak, D. Czekaj, Phase Transit. 79 (2006) 427-433.

[11] T. Ikeda, J. Phys. Soc. Jpn. 14 (1959) 168-174.

[12] D. Bochenek, R. Skulski, P. Wawrzala, D. Brzezinska, J. Alloys Comp. 509 (2011) 5356-5363.

[13] M. Adamczyk, L. Kozielski, A. Lisinska-Czekaj, D. Czekaj, J. Alloys Comp. 509 (2011) 6452-6456.

[14] L. Kozielski, M. Adamczyk, M. Pilch, Ceram. Int. 38 (2012) 3105-3109.

[15] M. Mir, V.R. Mastelaro, P.P. Neves, A.C. Doriguetto, D. Garcia, M.H. Lente, J.A. Eiras, Y.P. Mascarenhas, Acta Crystallogr. B 63 (2007) 713-718.

[16] G. Li, G. Heartling, Ferroelectrics 166 (1995) 31-45.

[17] A. Mesquita, A. Michalowicz, V.R. Masrelaro, Phase Transit. 85 (2012) 659-674.

[18] S. Sharma, R. Singh, T.C. Goel, S. Chandra, Comp. Mater. Sci. 37 (2006) 86-89.

[19] G.A. Samara, Ferroelectricity Revisited - Advances in Materials and Physics, Academic, New York, 2001.

[20] P.P. Neves, A.C. Doriguetto, V.R. Mastelaro, L.P. Lopes, Y.P. Mascarenhas, A. Michalowicz, J.A. Eiras, J. Phys. Chem. B 108 (2004) 14840-14849.

[21] B. Ravel, E.A. Stern, R.I. Vedrinskii, V. Kraizman, Ferroelectrics 206 (1998) $407-$ 430.

[22] V.A. Shuvaeva, D. Zekria, A.M. Glazer, Q. Jiang, S.M. Weber, P. Bhattacharya, P.A. Thomas, Phys. Rev. B 71 (2005) 174114.

[23] Y. Hwu, Y.D. Yao, N.F. Cheng, C.Y. Tung, H.M. Lin, Nanostruct. Mater. 9 (1997) 355-358.

[24] R. Ruus, A. Kikas, A. Saar, A. Ausmees, E. Nommiste, J. Aarik, A. Aidla, T. Uustare, I. Martinson, Solid State Commun. 104 (1997) 199-203.

[25] R.S. Liu, Y.C. Cheng, J.M. Chen, R.G. Liu, J.L. Wang, J.C. Tsai, M.Y. Hsu, Mater. Lett. 37 (1998) 285-289. 
[26] K. Asokan, J.C. Jan, J.W. Chiou, W.F. Pong, M.H. Tsai, H.L. Shih, H.Y. Chen, H.C. Hsueh, C.C. Chuang, Y.K. Chang, Y.Y. Chen, I.N. Lin, J. Phys. Condens. Mat. 13 (2001) 11087-11095.

[27] J.C. Jan, K.P.K. Kumar, J.W. Chiou, H.M. Tsai, H.L. Shih, H.C. Hsueh, S.C. Ray, K. Asokan, W.F. Pong, M.H. Tsai, S.Y. Kuo, W.F. Hsieh, Appl. Phys. Lett. 83 (2003) $3311-3313$.

[28] A. Michalowicz, J. Moscovici, D. Muller-Bouvet, K.J. Provost, Phys. Conf. Ser. 190 (2009) 012034

[29] A.L. Ankudinov, B. Ravel, S.D. Conradson, J.J. Rehr, Phys. Rev. B 58 (1998) 7565.

[30] L.J. Farrugia, J. Appl. Crystallogr. 30 (1997) 565.

[31] B. Ravel, E.A. Stern, Physica B 208 (1995) 316-318.

[32] R.V. Vedrinskii, V.L. Kraizman, A.A. Novakovich, P.V. Demekhin, S.V. Urazhdin, J. Phys. Condens. Mat. 10 (1998) 9561-9580.

[33] A.I. Frenkel, D.M. Pease, J. Giniewicz, E.A. Stern, D.L. Brewe, M. Daniel, J. Budnick, Phys. Rev. B 70 (2004) 014106.

[34] V.L. Kraizman, A.A. Novakovich, R.V. Vedrinskii, V.A. Timoshevskii, Physica B 208 (1995) 35-36.

[35] V.R. Mastelaro, A.C. Doriguetto, P.P. Neves, D. Garcia, M.H. Lente, Y.P. Mascarenhas, A. Michalowicz, J.A. Eiras, Ferroelectrics 339 (2006) 19051912.

[36] Y.A. Abramov, V.G. Tsirelson, V.E. Zavodnik, S.A. Ivanov, I.D. Brown, Acta Crystallogr. B 51 (1995) 942-951.

[37] N. Sicron, B. Ravel, Y. Yacoby, E.A. Stern, F. Dogan, J.J. Rehr, Phys. Rev. B 50 (1994) 13168-13180.

[38] S. Teslic, T. Egami, D. Viehland, J. Phys. Chem. Solids 57 (1996) $1537-$ 1543.

[39] T. Egami, S. Teslic, W. Dmowski, D. Viehland, S. Vakhrushev, Ferroelectrics 199 (1997) 103-113.

[40] K. Tsuda, R. Sano, M. Tanaka, Phys. Rev. B 86 (2012) 214106.

[41] P. Shanthakumar, M. Balasubramanian, D.M. Pease, A.I. Frenkel, D.M. Potrepka, V. Kraizman, J.I. Budnick, W.A. Hines, Phys. Rev. B 74 (2006) 174103.
[42] J.P. Itie, B. Couzinet, A.M. Flank, P. Lagarde, A. Polian, In X-Ray Absorption Fine Structure-XAFS13, in: B. Hedman, P. Painetta (Eds.), Amer Inst Physics, Melville, 2007, p. 241.

[43] V.R. Mastelaro, A. Mesquita, P.P. Neves, A. Michalowicz, M. Bounif, P.S. Pizani, M.R. Joya, J.A. Eiras, J. Appl. Phys. 105 (2009) 033508.

[44] V.R. Mastelaro, P.P. Neves, A. Michalowicz, J.A. Eiras, AIP Conf. Proc. 882 (2007) 496-498.

[45] I. Grinberg, P. Juhas, P.K. Davies, A.M. Rappe, Phys. Rev. Lett. 99 (2007) 267603.

[46] I. Grinberg, A.M. Rappe, Phys. Rev. B 70 (2004) 220101.

[47] R.E. Cohen, Nature 358 (1992) 136-138.

[48] G.A. Samara, Phys. Rev. Lett. 77 (1996) 314-317.

[49] F.M.F. De Groot, J.C. Fuggle, B.T. Thole, G.A. Sawatzky, Phys. Rev. B 41 (1990) 928-937.

[50] P. Nachimuthu, S. Thevuthasan, E.M. Adams, W.J. Weber, B.D. Begg, B.S. Mun, D.K. Shuh, D.W. Lindle, E.M. Gullikson, R.C.C. Perera, J. Phys. Chem. B 109 (2005) 1337-1339.

[51] J.C. Jan, H.M. Tsai, C.W. Pao, J.W. Chiou, C.K. Asokan, K.P.K. Kumar, W.F. Pong, Y.H. Tang, M.H. Tsai, S.Y. Kuo, W.F. Hsieh, Appl. Phys. Lett. 87 (2005) 012103.

[52] S.O. Kucheyev, T.v. Buuren, T.F. Baumann, JJH. Satcher, T.M. Willey, R.W. Meulenberg, T.E. Felter, J.F. Poco, S.A. Gammon, L.J. Terminello, Phys. Rev. B 69 (2004) 245102.

[53] P. Krüger, Phys. Rev. B 81 (2010) 125121.

[54] H. Miyazawa, E. Natori, S. Miyashita, T. Shimoda, F. Ishii, T. Oguchi, Jpn. J. Appl. Phys. 1 (39) (2000) 5679-5682.

[55] K. Asokan, J.C. Jan, J.W. Chiou, W.F. Pong, M.H. Tsai, Y.K. Chang, Y.Y. Chen, H.H. Hsieh, H.J. Lin, Y.W. Yang, L.J. Lai, I.N. Lin, J. Solid State Chem. 177 (2004) 26392643.

[56] Y.X. Wang, W.L. Zhong, C.L. Wang, P.L. Zhang, Chinese Phys. Lett. 18 (2001) $826-828$.

[57] V.R. Mastelaro, P.P. Neves, A. Michalowicz, J.A. Eiras, J. Phys. Condens. Mat. 19 (2007) 226212 